\title{
Distinct Regulation of Cardiac Fibroblast Proliferation and Transdifferentiation by Classical and Novel Protein Kinase C Isoforms: Possible Implications for New Antifibrotic Therapies $\$$
}

\author{
S. Tuuli Karhu, Heikki Ruskoaho, and (1)Virpi Talman \\ Drug Research Program and Division of Pharmacology and Pharmacotherapy, Faculty of Pharmacy, University of Helsinki, \\ Finland
}

Received June 16, 2020; accepted November 16, 2020

\begin{abstract}
Cardiac fibrosis is characterized by accumulation and activation of fibroblasts and excessive production of extracellular matrix, which results in myocardial stiffening and eventually leads to heart failure. Although previous work suggests that protein kinase $C$ (PKC) isoforms play a role in cardiac fibrosis and remodeling, the results are conflicting. Moreover, the potential of targeting PKC with pharmacological tools to inhibit pathologic fibrosis has not been fully evaluated. Here we investigated the effects of selected PKC agonists and inhibitors on cardiac fibroblast (CF) phenotype, proliferation, and gene expression using primary adult mouse CFs, which spontaneously transdifferentiate into myofibroblasts in culture. A 48-hour exposure to the potent PKC activator phorbol 12-myristate 13-acetate (PMA) at $10 \mathrm{nM}$ concentration reduced the intensity of $\alpha$-smooth muscle actin staining by $56 \%$ and periostin mRNA levels by $60 \%$ compared with control. The decreases were inhibited with the pan-PKC inhibitor Gö6983 and the inhibitor of classical PKC isoforms Gö6976, suggesting that classical PKCs regulate CF transdifferentiation. PMA also induced a 33\% decrease in 5bromo-2'-deoxyuridine-positive CFs, which was inhibited with Gö6983 but not with Gö6976, indicating that novel PKC isoforms
\end{abstract}

(nPKCs) regulate CF proliferation. Moreover, PMA downregulated the expression of collagen-encoding genes Col1a1 and Co/3a1 nPKC-dependently, showing that PKC activation attenuates matrix synthesis in CFs. The partial PKC agonist isophthalate derivative bis(1-ethylpentyl) 5-(hydroxymethyl)isophthalate induced parallel changes in phenotype, cell cycle activity, and gene expression. In conclusion, our results reveal distinct PKCdependent regulation of CF transdifferentiation and proliferation and suggest that PKC agonists exhibit potential as an antifibrotic treatment.

\section{SIGNIFICANCE STATEMENT}

Cardiac fibrosis is a pathological process that contributes to the development of heart failure. The molecular mechanisms regulating fibrosis in the heart are, however, not fully understood, which hinders the development of new therapies. Here, we demonstrate that classical and novel protein kinase $C$ (PKC) isoforms distinctly regulate cardiac fibroblast transdifferentiation and proliferation, the two central processes in fibrosis. Our results indicate that pharmacological PKC activation may be a promising strategy to inhibit myocardial fibrosis.

\section{Introduction}

Cardiac fibrosis is characterized by transdifferentiation of fibroblasts into secretory and contractile myofibroblasts and concomitant accumulation of extracellular matrix in the myocardium (Kong et al., 2014). Although several cell types can contribute to fibrotic remodeling indirectly by secreting profibrotic factors, resident cardiac fibroblasts $(\mathrm{CFs})$ are the

The research was supported by the Finnish Foundation for Cardiovascular Research, Business Finland [project no. 40395/13, 3iRegeneration], the Sigrid Jusélius Foundation, the Academy of Finland [Grant 321564], and the Finnish Cultural Foundation.

https://doi.org/10.1124/molpharm.120.000094

S This article has supplemental material available at molpharm. aspetjournals.org. key cell type responsible for fibrosis. Upon pathologic stimuli, CFs become activated and transdifferentiate into myofibroblasts, which exhibit characteristics of both fibroblasts and smooth muscle cells and produce high amounts of extracellular matrix proteins (Talman and Ruskoaho, 2016). The fibrotic response is a crucial part of the healing process after a myocardial infarction (van den Borne et al., 2010; Shinde and Frangogiannis, 2014). However, prolonged fibroblast activation in remote areas outside the initial insult area or due to other stimuli, such as pressure overload, leads to adverse myocardial remodeling and progressive impairment of cardiac function. Cardiac fibrosis has been identified as an independent risk factor in heart failure (Gulati et al., 2013): it was associated independently, beyond left ventricular ejection

ABBREVIATIONS: BrdU, 5-bromo-2'-deoxyuridine; CF, cardiac fibroblast; Cl, confidence interval; cPKC, classical protein kinase C isoform; DAG, diacylglycerol; DAPI, 4',6-diamidino-2-phenylindole; DB, Dulbecco's PBS containing $0.2 \%$ bovine serum albumin; DDR2, discoidin domain receptor 2; ERK1/2, extracellular signal-regulated kinases 1/2; HCA, high-content analysis; HMI-1b11, bis(1-ethylpentyl) 5-(hydroxymethyl) isophthalate; $\mathrm{LDH}$, lactate dehydrogenase; MTT, 3-(4,5-dimethylthiazol-2-yl)-2,5-diphenyltetrazolium bromide; nPKC, novel protein kinase C isoform; p-ERK1/2, phosphorylated extracellular signal-regulated kinases 1/2; PKC, protein kinase C; PMA, phorbol 12-myristate 13-acetate; qPCR, quantitative polymerase chain reaction; r.t., room temperature; $\alpha$-SMA, $\alpha$-smooth muscle actin; TGF $\beta$, transforming growth factor; TTBS, Tris-buffered saline with $0.05 \%$ Tween 20 . 
fraction, with mortality and sudden cardiac death in patients with dilated cardiomyopathy. Slowing or reversing cardiac fibrosis is a therapeutic goal in heart failure therapy (Cohn et al., 2000).

Protein kinase C (PKC) is a group of ten related serinethreonine protein kinases, which are known to participate in various signaling pathways and thus regulate, for example, cell proliferation, differentiation, migration, gene transcription and translation, and cell death (Mochly-Rosen et al., 2012). PKC isoforms can be divided into three subgroups based on their regulatory region structure and activator requirements (Steinberg, 2008). The classical isoforms (cPKCs; $\alpha, \beta \mathrm{I}, \beta \mathrm{II}$, and $\gamma$ ) require both diacylglycerol (DAG) and calcium for their activation, whereas the novel isoforms (nPKCs; $\delta, \varepsilon, \eta$, and $\theta$ ) are activated by DAG alone. A more distant subgroup of atypical isoforms $(\zeta$ and $\lambda / \iota$ ) does not respond to either DAG or calcium. The expression of PKC isoenzymes in myocardium varies between species but also between normal and diseased state (Palaniyandi et al., 2009). In the adult human heart, for instance, all isoforms except for $\gamma$ and $\theta$ have been detected (Shin et al., 2000; Simonis et al., 2007). On the other hand, dilated cardiomyopathy leads to upregulation of $\mathrm{PKC} \beta$ (Bowling et al., 1999), whereas aortic stenosis leads to upregulation of several isoforms but not $\operatorname{PKC} \beta$ (Simonis et al., 2007).

The roles of individual PKC isoforms have been investigated using genetic knockdown and overexpression models, as well as pharmacological inhibitors. The majority of the reports suggest that PKC promotes fibrosis. The ATP-competitive $\operatorname{PKC} \beta$ inhibitor ruboxistaurin reduced cardiac fibrosis and dysfunction after myocardial infarction in rats (Boyle et al., 2005) and in mice subjected to pressure overload (Liu et al., 2009). It also attenuated collagen deposition in a rat diabetic cardiomyopathy model (Connelly et al., 2009). Moreover, selective inhibition of $\mathrm{PKC} \beta \mathrm{II}$ with a translocation peptide inhibitor suppressed myocardial fibrosis in hypertensive rats (Ferreira et al., 2011). Regarding novel PKC isoforms, pharmacological inhibition of $\mathrm{PKC} \varepsilon$ with a selective translocation peptide inhibitor reduced fibrosis in hypertensive rats and collagen secretion from cultured primary CFs stimulated with transforming growth factor $\beta$ (TGF $\beta$ ) (Inagaki et al., 2008). However, there are also contradictory reports suggesting that $\mathrm{PKC}$ may in fact have a role in limiting cardiac fibrosis. PKC $\varepsilon$ knockout mice showed increased fibrosis and elevated expression of collagen I and III in response to pressure overload (Klein et al., 2005). Moreover, in vitro selective inhibition of $\mathrm{PKC} \delta$ with a translocation peptide inhibitor promoted neonatal rat CF proliferation (Braun and Mochly-Rosen, 2003).

The aim of this study was to investigate the effect of pharmacological PKC activation on viability, cell cycle activity, phenotype, and gene expression of adult mouse primary CFs in vitro. The compounds include the potent tumorpromoting PKC activator phorbol 12-myristate 13-acetate (PMA) and the isophthalate derivative bis(1-ethylpentyl) 5-(hydroxymethyl)isophthalate (HMI-1b11), both of which activate PKC by binding to the DAG binding sites within duplicated $\mathrm{C} 1$ domains in cPKCs and nPKCs (Boije af Gennäs et al., 2009, 2011). To clarify the role of different PKC subfamilies, two PKC inhibitors, Gö6976 and Gö6983, which differ in their selectivity toward cPKCs and nPKCs, were used. Our results demonstrate that cPKCs and nPKCs distinctly regulate proliferation and transdifferentiation of
CFs, the two central cellular processes in the development of cardiac fibrosis, and indicate that fibroblast-targeted PKC activation may be a potential therapeutic strategy to inhibit cardiac fibrosis.

\section{Materials and Methods}

Materials. Cell culture media and supplements were purchased from Gibco (Thermo Fisher Scientific, Paisley, UK). Enzyme P, Red Blood Cell Lysis Solution $(10 \times)$, gentleMACS C tubes, and gentleMACS Dissociator were from Miltenyi Biotec (Bergisch Gladbach, Germany). DNase I was purchased from AppliChem (Darmstadt, Germany), Collagenase type 2 from Worthington Biochemical Corporation (Lakewood, NJ), and gelatin from Merck Millipore (Darmstadt, Germany). PMA was purchased from Sigma-Aldrich (Steinheim, Germany). Diheptan-3-yl 5-(hydroxymethyl)isophthalate (HMI1b11) was synthesized at the Division of Pharmaceutical Chemistry and Technology, Faculty of Pharmacy, University of Helsinki, as described previously (Boije af Gennäs et al., 2009). PKC inhibitors Gö6976 and Gö6983 were purchased from Merck Millipore (Billerica, MA). All reagents used in the cytotoxicity assays were from SigmaAldrich. AlphaLISA SureFire Ultra p-ERK 1/2 (Thr202/Tyr204) and AlphaLISA SureFire Ultra Total ERK 1/2 assay kits were from PerkinElmer (Groningen, The Netherlands).

Trans-Blot Turbo Midi PVDF Transfer Packs and 12\% MiniProtean TGX Stain-Free Protein Gels were purchased from Bio-Rad. Pierce BCA Protein Assay Kit and SuperSignal West Femto Maximum Sensitivity Substrate were from Thermo Scientific. The primary antibodies used in Western blotting were monoclonal rabbit anti-PKC alpha (ab32376; Abcam), monoclonal rabbit anti-PKC delta (ab182126; Abcam), monoclonal rabbit anti-PKC epsilon (ab124806; Abcam), monoclonal rabbit anti-PKC eta (ab179524; Abcam), and polyclonal rabbit anti- $\beta$-actin (4967; Cell Signaling Technology). The secondary horseradish peroxidase-linked antibody anti-rabbit lgG (7074) was from Cell Signaling Technology.

5-Bromo-2'-deoxyuridine (BrdU) was purchased from Abcam (Cambridge, UK). The primary antibodies used in immunofluorescence stainings were monoclonal mouse anti- $\alpha$-smooth muscle actin ( $\alpha$-SMA; A2547; Sigma-Aldrich), polyclonal rabbit anti-discoidin domain receptor 2 (DDR2) (sc-8989; Santa Cruz Biotechnology), monoclonal rat anti-BrdU (ab6326; Abcam), and polyclonal rabbit anti-Ki67 (ab15580; Abcam). The secondary antibodies used were all purchased from Life Technologies: Alexa Fluor 488 goat anti-mouse lgG (A11029), Alexa Fluor 546 donkey anti-rabbit lgG (A10040), and Alexa Fluor 647 goat anti-rat lgG (A21247), with the exception of Alexa Fluor 594 goat anti-rabbit lgG (ab150080), which was from Abcam. 4',6-diamidino-2-phenylindole (DAPI) was from SigmaAldrich.

NucleoSpin RNA kit was from Macherey-Nagel (Düren, Germany). Transcriptor First Strand cDNA Synthesis kit and LightCycler 480 Probes Master kit were from Roche. TaqMan gene expression assays for 18S (Hs99999901_s1),Actb (Mm00607939_s1),_Acta2 (Mm01546133_m1), Col1a1 (Mm00801666_g1), Col1a2 (Mm00483888_m1), Col3a1 (Mm00802300_m1), Fn1 (Mm01256744_m1), Mmp2 (Mm00439498_m1), Mmp9 (Mm00442991_m1), Myh10 (Mm00805131_m1), Postn (Mm01284919_m1), Tgfb1 (Mm01178820_m1), and Tcf21 (Mm00448961_m1) were purchased from Thermo Fisher Scientific.

Primary Cardiac Fibroblasts. Primary cultures of CFs were prepared from 10-20-week-old female C57BL/6JOlaHsd mice weighing 20-22 g (Envigo, Horst, The Netherlands). Animals were euthanized by $\mathrm{CO}_{2}$ narcosis followed by cervical dislocation. Thoracic cavities were opened, and hearts were perfused through aortas with $2.5 \mathrm{ml}$ of $500 \mathrm{U} / \mathrm{ml}$ collagenase II in PBS using a $27 \mathrm{G} 12 \mathrm{~mm}$ needle. Ventricles were dissected, cut into small pieces, and transferred into gentleMACS $\mathrm{C}$ tubes (two hearts/tube) containing $5 \mathrm{ml}$ enzyme solution (Dulbecco's modified Eagle's medium containing $400 \mathrm{U} / \mathrm{ml}$ collagenase II, $60 \mathrm{U} / \mathrm{ml}$ DNase I, and $10 \mu \mathrm{l} / \mathrm{ml}$ enzyme P). The tissue 
pieces were first incubated at $37^{\circ} \mathrm{C}$ under $300 \mathrm{rpm}$ shaking conditions for 20 minutes, followed by mechanical digestion with gentleMACS Dissociator (program $m \_m u s c l e \_01$ ). Enzymatic digestion was continued with a 30 -minute incubation at $37^{\circ} \mathrm{C}$ under $600 \mathrm{rpm}$ shaking conditions followed by a second mechanical digestion. The lysate was quickly centrifuged at $300 \mathrm{~g}, 4^{\circ} \mathrm{C}$, and tissue debris was separated from the cell suspension with a $250 \mu \mathrm{m}$ tissue strainer. The cell suspension was centrifuged at $300 \mathrm{~g}, 4^{\circ} \mathrm{C}$ for 10 minutes. The cell pellet was resuspended in a buffer solution containing $0.5 \%$ bovine serum albumin and $2 \mathrm{mM}$ EDTA in PBS, $\mathrm{pH}$ 7.2. To remove erythrocytes, red blood cell lysis solution was added according to the manufacturer's protocol and incubated for 2 minutes at room temperature (r.t.). After centrifuging the sample for 10 minutes at $300 g, 4^{\circ} \mathrm{C}$ and aspirating the supernatant, the cells were washed with medium used for fibroblast culture (Dulbecco's modified Eagle's medium/F-12 supplemented with $10 \% \mathrm{FBS}, 100 \mathrm{U} / \mathrm{ml}$ penicillin, and $100 \mu \mathrm{g} / \mathrm{ml}$ streptomycin), and centrifuged again for 10 minutes at $300 \mathrm{~g}, 4^{\circ} \mathrm{C}$. The cells were then resuspended in culture medium, plated on well plates and let attach for 2 hours in cell culture conditions $\left(37^{\circ} \mathrm{C}\right.$, humidified atmosphere of $5 \% \mathrm{CO}_{2}$ ). To remove dead cells, the medium was changed before letting the cells grow overnight prior to compound treatments. For gene expression and phenotypic studies, cells were grown on gelatin-coated microscope cover glasses, whereas for viability and cellular kinase assays and high-content analysis (HCA) they were grown on plastic 96-well plates and for Western blotting on plastic six-well plates.

Cell Viability Assays. The cells were exposed to the compounds (1-100 nM PMA, 1-30 $\mu$ M HMI-1b11, 0.1-10 $\mu \mathrm{M}$ Gö6976, 0.1-10 $\mu \mathrm{M}$ Gö6983) for 24 hours after which necrosis and mitochondrial metabolism were investigated using the lactate dehydrogenase (LDH) and the 3-(4,5-dimethylthiazol-2-yl)-2,5-diphenyltetrazolium bromide (MTT) assays, respectively, as described previously (Talman et al., 2011). For the LDH assay, $50 \mu \mathrm{l}$ of culture medium was transferred from each well onto a new 96 -well plate followed by addition of $50 \mu \mathrm{l}$ substrate solution containing $1.3 \mathrm{mM} \beta$-nicotinamide adenine dinucleotide, $660 \mu \mathrm{M}$ iodonitrotetrazolium, $54 \mathrm{mM} \mathrm{L(+)-lactic} \mathrm{acid,}$ $280 \mu \mathrm{M}$ phenazine methosulfate, and 0.2 M Tris-HCl (pH 8.0). After a 30-minute incubation at r.t. the reaction was stopped by adding $50 \mu \mathrm{l}$ of $1 \mathrm{M}$ acetic acid to each well, and absorbance was measured at $490 \mathrm{~nm}$ using Victor2 plate reader (PerkinElmer, Turku, Finland). Spontaneous LDH release was measured from untreated cells, maximal LDH release from cells lysed with $0.9 \%$ Triton X-100, and background absorbance from wells without cells (medium only). After subtracting background, cytotoxicity was calculated as follows: cytotoxicity percentage $=[($ sample - spontaneous LDH release $) /($ maximal $\mathrm{LDH}$ release - spontaneous $\mathrm{LDH}$ release) $\times 100$. For the MTT assay, MTT was added to the cells at a final concentration of $0.5 \mathrm{mg} / \mathrm{ml}$ followed by a 2 -hour incubation in cell culture conditions. The medium was aspirated and formazan crystals were solubilized in DMSO. Absorbance was measured at $550 \mathrm{~nm}$, and absorbance at $650 \mathrm{~nm}$ was subtracted as background.

Cellular Kinase Assay. The cells were exposed to the compounds (10 nM PMA or $10 \mu \mathrm{M}$ HMI-1b11 with or without $1 \mu \mathrm{M}$ Gö6976 or $1 \mu \mathrm{M}$ Gö6983) for 30 minutes after which they were lysed and the amount of phosphorylated extracellular signal-regulated kinases $1 / 2(\mathrm{p}-\mathrm{ERK} 1 / 2)$ and total extracellular signal-regulated kinases 1/2 (ERK1/2) were detected using AlphaLISA SureFire Ultra p-ERK 1/2 (Thr202/Tyr204) and AlphaLISA SureFire Ultra Total ERK 1/2 assay kits according to the manufacturer's protocol. The cells were lysed in $80 \mu \mathrm{l}$ lysis buffer, and $30 \mu \mathrm{l}$ of the lysate was transferred from each well to two 96-well 1/2 AreaPlates (PerkinElmer) for assays. The lysates were then incubated with the Acceptor bead mix for 1 hour at r.t., followed by addition of the Donor bead mix and a further 5-hour incubation at r.t. The Alpha signal was measured using EnSpire Alpha plate reader (PerkinElmer, Turku, Finland) with standard AlphaLISA settings.

Western Blotting. The cells were exposed to the compounds (10 nM PMA or $10 \mu \mathrm{M}$ HMI-1b11 with or without $1 \mu \mathrm{M}$ Gö6983) for 48 hours after which they were lysed with $1 \%$ SDS in $50 \mathrm{mM}$ Tris-HCl
( $\mathrm{pH}$ 7.5), and genomic DNA was sheared with a 25 G needle. Protein concentrations were determined with bicinchoninic acid protein assay kit. From each sample $10 \mu \mathrm{g}$ of total protein was resolved on a $12 \%$ Mini-protean TGX stain-free gel and transferred by TransBlot Turbo transfer system to polyvinylidene difluoride membranes. After blocking the nonspecific background with 5\% nonfat milk in Tris-buffered saline with $0.05 \%$ Tween 20 (TTBS) for 1 hour at r.t., the membranes were incubated with primary antibodies (anti-PKC $\alpha$ 1:1000, anti-PKC $\delta$ 1:5000, anti-PKC $\varepsilon$ 1:1000, anti-PKC $\eta$ 1:2000, anti- $\beta$-actin 1:1000 dilution in $5 \%$ milk-TTBS) overnight at $4^{\circ} \mathrm{C}$. After washing with TTBS, the membranes were incubated for 1 hour at r.t. with horseradish peroxidase-conjugated secondary antibody (1:2000 dilution in 5\% milk-TTBS). Bands were detected with an enhanced chemiluminescent substrate using ChemiDoc XRS+ (Bio-Rad) or Luminescent Imager Analyzer LAS-3000 (Fujifilm) and relative densities were quantified using Fiji ImageJ 1.52 software. Optical densities of PKC isoform immunoreactive bands were adjusted to corresponding $\beta$-actin bands from the same membranes.

Nonautomated Fluorescence Microscopy and Phenotypic Analysis. The cells were grown in mere cell culture medium for 1-3 days after cell isolation or they were exposed to PKC agonists (10 nM PMA or $10 \mu \mathrm{M}$ HMI-1b11) and inhibitors (1 $\mu \mathrm{M}$ Gö6976 or $1 \mu \mathrm{M}$ Gö6983) 24 hours after isolation for 48 hours. The cells were fixed with $4 \%$ paraformaldehyde for 15 minutes at r.t. and permeabilized with $0.1 \%$ Triton X-100 for 10 minutes. The cells were then washed $2 \times 10$ minutes with Dulbecco's PBS containing $0.2 \%$ bovine serum albumin (DB) and incubated at r.t. for 60 minutes with primary antibodies: anti- $\alpha$-SMA (1:200) and anti-DDR2 (1:50) diluted in DB. After three 5-minute washes with DB, the cells were incubated with Alexa Fluor-conjugated secondary antibodies (1:200) and DAPI $(1 \mu \mathrm{g} / \mathrm{ml})$ at r.t. for 45 minutes. After three 5-minute washes, the microscope cover glasses were mounted on microscope slides with Prolong Gold Antifade Mountant and imaged with Leica DM6000B fluorescence wide field microscope (Leica Microsystems, Wetzlar, Saksa) and CMOS camera (Hamamatsu Orca-Flash4.0 V2, Hamamatsu Photonics, Hamamatsu, Japan). The objective was $20 \times / 0.7$ HC PL APO CS, and the software was Leica Application Suite X (Leica Microsystems, Wetzlar, Germany). The images were analyzed using CellProfiler image analysis software. For quantification, the cells were first identified based on DAPI fluorescence, which defined the nuclear area, and the cell area was defined by extending the nuclear area with the area defined by DDR2 staining. Integrated intensity of $\alpha$-SMA staining was then quantified from each individual cell.

Automated Fluorescence Microscopy and High Content Analysis. For HCA of CF proliferation, the cells were stained, imaged, and analyzed as described previously (Karhu et al., 2018). The cells were exposed to the compounds (10 nM PMA or $10 \mu \mathrm{M}$ HMI$1 \mathrm{~b} 11$ with or without $1 \mu \mathrm{M}$ Gö6976 or $1 \mu \mathrm{M}$ Gö6983) for 48 hours, and $10 \mu \mathrm{M}$ BrdU was added to the culture medium for the last 24 hours before fixation. The cells were fixed with $4 \%$ paraformaldehyde for 15 minutes at r.t. and permeabilized with $0.1 \%$ Triton X-100 for 10 minutes. DNA was hydrolyzed with $2 \mathrm{M} \mathrm{HCl}$ for 30 minutes (r.t.) followed by neutralization with $0.1 \mathrm{M}$ sodium borate $(\mathrm{pH}$ 8.5) for 30 minutes. Nonspecific binding sites were blocked with $4 \%$ FBS in PBS for 45 minutes (r.t.). The cells were incubated 60 minutes with primary antibodies: anti- $\alpha$-SMA (1:200), anti-BrdU (1:250), and antiKi67 (1:250) diluted in 4\% FBS. After $3 \times 5$-minute washes with PBS, the cells were incubated with Alexa Fluor-conjugated secondary antibodies (1:200) and DAPI $(1 \mu \mathrm{g} / \mathrm{ml})$ at r.t. for 45 minutes. The 96-well plates were imaged and analyzed with CellInsight CX5 HighContent Screening Platform (Thermo Scientific) using a $10 \times$ objective (Olympus UPlanFL N 10×/0.3). For quantification of BrdU-positive and Ki67-positive CFs, the cells were first identified based on DAPI fluorescence, which defined the nuclear area. The thresholds for BrdU+ and Ki67+ cells were set manually in each experiment to adjust for slight variation in staining intensities.

Quantitative Real-Time Polymerase Chain Reaction. The cells were exposed to the compounds (10 nM PMA or $10 \mu \mathrm{M}$ HMI-1b11 
with or without $1 \mu \mathrm{M}$ Gö6976 or $1 \mu \mathrm{M}$ Gö6983) for 48 hours, after which they were lysed, and RNA was isolated using NucleoSpin RNA kit (Macherey-Nagel, Düren, Germany) according to the manufacturer's protocol. Samples were lysed in $350 \mu l$ lysis buffer containing $1 \% \beta$-mercaptoethanol. Total RNA was transcribed into cDNA with Transcriptor First Strand cDNA Synthesis kit (Roche, Mannheim, Germany) following the manufacturer's protocol using random hexamer primers. Quantitative polymerase chain reaction (qPCR) was performed using TaqMan assays (Thermo Fisher Scientific), LightCycler 480 Probes Master kit (Roche), and LightCycler 480 Real-Time PCR machine (Roche). The results were analyzed using the $\Delta \Delta \mathrm{Ct}$ method and adjusted to the average of two housekeeping genes (18S and Actb) from the same samples.

Ethics. The animals were housed and terminated in accordance with the $3 R$ principles of the European Union directive 2010/63/EU governing the care and use of experimental animals, and following local laws and regulations [Finnish Act on the Protection of Animals Used for Scientific or Educational Purposes (497/2013), Government Decree on the Protection of Animals Used for Scientific or Educational Purposes (564/2013)]. The use of animals for collecting tissues was reviewed and approved by Laboratory Animal Center, Helsinki Institute of Life Sciences, University of Helsinki (internal license KEK17-012).

Statistics. For statistical analysis, non-normalized raw data were used, with the exceptions of kinase assay for which total ERK1/2normalized values were used, qPCR for which $\Delta \mathrm{Ct}$ values were used, and Western blotting for which $\beta$-actin-adjusted values were used. Statistical analyses were performed using IBM SPSS Statistics 25 software. Statistical significance was evaluated with randomized block ANOVA (experiment and treatment as factors) followed by Dunnett's post hoc test. Differences at the level of $P<0.05$ were considered statistically significant.

\section{Results}

The Effect of PKC Agonists and Inhibitors on Cardiac Fibroblast Viability. We first examined the effect of PKC agonists and inhibitors on the viability of CFs. Based on the MTT assay, 24-hour exposure to PMA at the concentrations of $10 \mathrm{nM}$ and $100 \mathrm{nM}$ caused small $23 \%$ [95\% confidence interval (CI) $11-34 ; P=0.004]$ and $14 \%$ (95\% CI $0-30 ; P=0.062)$ decreases, respectively, in viability of CFs (Supplemental Fig. 1). Exposure to partial PKC agonist HMI-1b11 at the concentration of $30 \mu \mathrm{M}$ decreased metabolic activity $70 \%(95 \%$ CI $54-85 ; P<0.001$ ) but at $10 \mu \mathrm{M}$ concentration HMI-1b11 slightly increased it (28\%; 95\% CI 5-52; $P=0.025$ ), compared with control. A treatment with the pan-PKC inhibitor Gö6983 had no effect on CF viability, whereas the inhibitor of classical PKCs (Gö6976) decreased cell viability concentration-dependently: $17 \%(95 \%$ CI $12-22)$ at $1 \mu \mathrm{M}$ concentration and $39 \%(95 \%$ CI $30-48 ; P=0.004)$ at $10 \mu \mathrm{M}$ concentration. Based on the LDH assay results, only HMI-1b11 at the highest $30 \mu \mathrm{M}$ concentration exhibited a noticeable cytotoxic response; after a 24-hour exposure the LDH release was $35 \%$ of the maximal $(95 \%$ CI $27-45 ; P<0.001$; Supplemental Fig. 1). PMA and the PKC inhibitors induced less than $10 \%$ increase in cytotoxicity even with the highest concentrations. Concentrations for the proliferation and transdifferentiation experiments were selected based on the present results regarding toxicity and previous reports regarding in vitro efficacy of the compounds (Talman et al., 2013; Sarajärvi et al., 2018). Furthermore, as PMA induces downregulation of several PKC isoforms at $100 \mathrm{nM}$ (Johnson et al., 1995), the $10 \mathrm{nM}$ concentration was chosen to avoid downregulation.

The Effect of PKC Agonists and Inhibitors on ERK1/2 Phosphorylation in Cardiac Fibroblasts. To confirm the effect of PMA and HMI-1b11 on PKC, activation of mitogen activated protein kinase kinase-extracellular signal-regulated kinase pathway, a known downstream signaling pathway of PKC (Schönwasser et al., 1998; Mackay and Twelves, 2007), was studied by measuring ERK1/2 phosphorylation in CFs using AlphaLISA assay. A 30-minute exposure to PMA at $10 \mathrm{nM}$ concentration and HMI- $1 \mathrm{~b} 11$ at $10 \mu \mathrm{M}$ concentration induced 2.9-fold (95\% CI 1.9-4.0; $P=0.016$ ) and 2.6-fold (95\% CI 1.8-3.5; $P=0.037$ ) increases, respectively, in the amount of p-ERK1/2 compared with DMSO-control (Fig. 1A). Moreover, the increases in p-ERK1/2 were inhibited with the pan-PKC inhibitor Gö6983 but not with the cPKC inhibitor Gö6976, suggesting that PKC agonist-mediated ERK1/2 activation is mediated by $\mathrm{nPKCs}$ in CFs.

The Effect of PKC Agonists and Inhibitors on PKC Protein Levels in Cardiac Fibroblasts. We then analyzed PKC protein levels to verify the expression of selected isoenzymes in mouse $\mathrm{CFs}$ and to assess whether PMA or HMI-1b11 cause PKC downregulation in our experimental design. Based on our previous RNA sequencing data (Talman et al., 2018), the main PKC isoforms expressed in mouse heart are $\alpha, \delta, \varepsilon, \eta$, and $\lambda$ (the mouse homolog of human PKC $\iota$; Webb et al., 2000) (Supplemental Fig. 2). As the C1 domain of atypical $\mathrm{PKC} \lambda$ does not bind $\mathrm{C} 1$ domain ligands analogous to DAG, including PMA and HMI-1b11 (Steinberg, 2008; Talman et al., 2014b), only the classical $(\alpha)$ and novel $(\delta, \varepsilon$, and $\eta)$ isoforms of these five isoforms abundant in mouse hearts were selected for Western blot analysis. Firstly, all four isoforms were detected in total cell homogenates, and thus their expression in mouse cardiac (myo)fibroblasts was verified (Figs. 1, B-F). Secondly, neither PMA at $10 \mathrm{nM}$ concentration nor HMI-1b11 at $10 \mu \mathrm{M}$ concentration had effect on $\mathrm{PKC} \alpha$, $\mathrm{PKC} \varepsilon$, or $\mathrm{PKC} \eta$ protein levels after 48-hour exposure. However, both PKC activators induced a minor downregulation of $\mathrm{PKC} \delta$, which was not inhibited by coexposure to the pan-PKC inhibitor Gö6983. The PMA-induced decrease was $25 \%(95 \%$ CI $13-37 ; P=0.040)$ and HMI-1b11-induced decrease $34 \%$ (95\% CI 20-48; $P=0.003$ ) compared with control.

The Effect of PKC Agonists and Inhibitors on Cardiac Fibroblast Phenotype. To characterize the primary cell culture and to study the phenotype of CFs, we used DDR2 as a marker of fibroblasts and $\alpha$-SMA as a marker of myofibroblasts. DDR2 was chosen because within the heart it is only expressed in fibroblasts (Goldsmith et al., 2004). $\alpha$-SMA, on the other hand, is expressed in smooth muscle cells but also serves as a marker of activated and transdifferentiated fibroblasts, myofibroblasts, which have a key role in scar formation and myocardial remodeling after cardiac injury (van den Borne et al., 2010). Based on DDR2 expression, approximately $98 \%$ of the cells in the primary cultures were CFs (Supplemental Fig. 4). Moreover, when cultured in mere cell culture medium, CFs acquired a myofibroblast phenotype within 72 hours from plating as demonstrated by $\alpha$-SMA expression. The relative $\alpha$-SMA staining intensity increased 5.8-fold (95\% CI 1.9-9.7; $P=0.030$ ) between 24- and 72-hour time points (Supplemental Fig. 4). This spontaneous phenotypic 


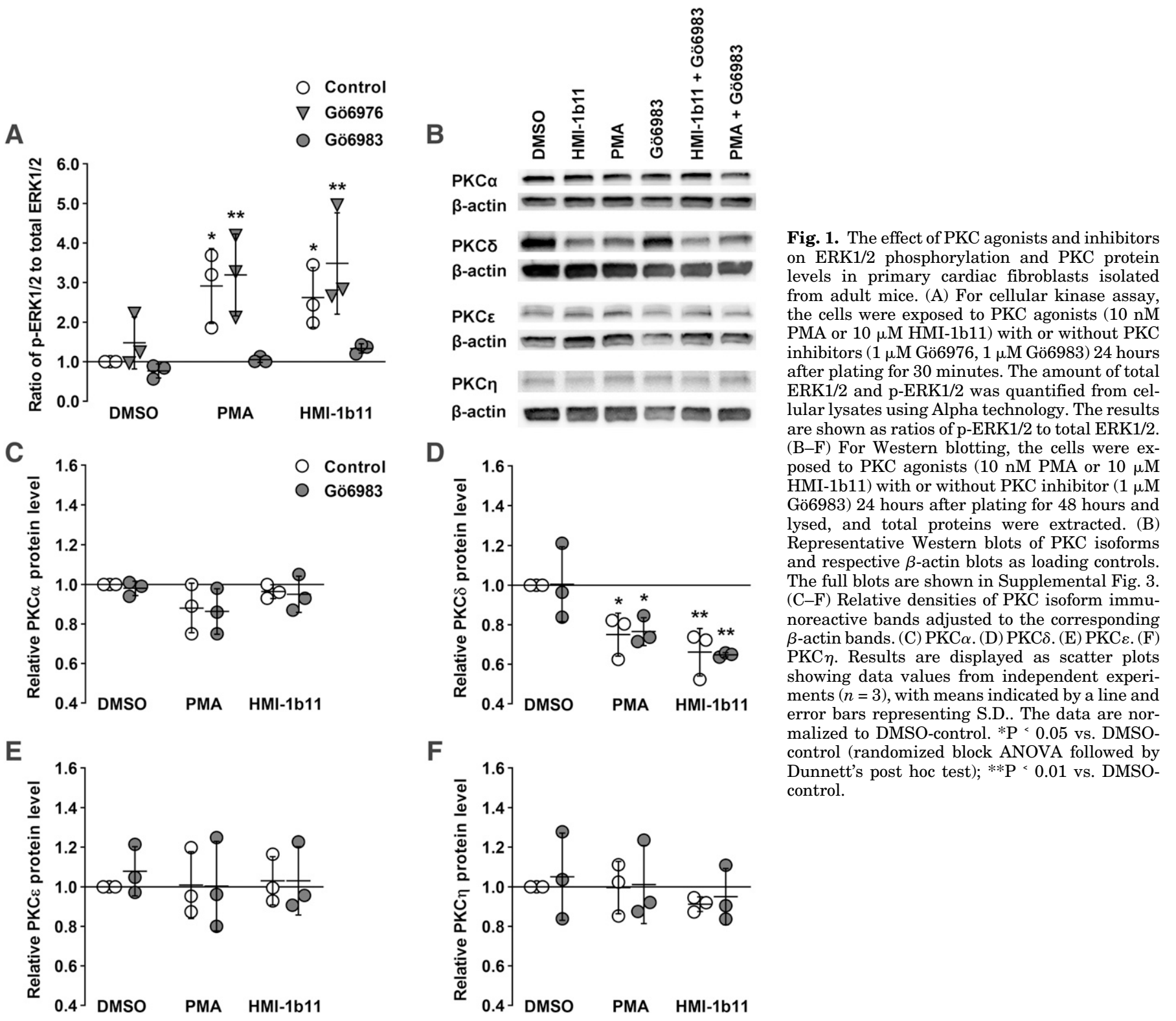

change (previously reported in Wang et al., 2003) was then further used to investigate the effects of PKC agonists on CF transdifferentiation. Both PKC agonists, PMA at $10 \mathrm{nM}$ and HMI-1b11 at $10 \mu \mathrm{M}$ concentration, inhibited fibroblast transdifferentiation to myofibroblasts after 48-hour exposure (Fig. 2, A and B). PMA induced a 56\% reduction (95\% CI $47-65 ; P=0.011$ ) in the integrated intensity of $\alpha$-SMA staining compared with DMSO-control (Fig. 2C). This decrease appeared to be cPKC dependent as it was prevented with both the cPKC inhibitor Gö6976 and the pan-PKC inhibitor Gö6983. Also HMI-1b11 decreased the expression of $\alpha$-SMA by $34 \%$ (95\% CI 33-35; $P=0.018$ ), and the inhibitors partially attenuated the effect. The inhibitors alone had no effect on $\alpha$-SMA expression (Fig. 2C).

The Effect of PKC Agonists and Inhibitors on Cardiac Fibroblast Proliferation. To investigate the effect of PKC activation on cell cycle activity of CFs, HCA of BrdU and Ki67 stainings was used. After a 48-hour exposure,
PMA induced a $33 \%$ decrease $(95 \%$ CI $24-42 ; P=0.018)$ in BrdU-positive and a $36 \%$ decrease $(95 \%$ CI $8-64 ; P=0.008)$ in Ki67-positive CFs compared with DMSO-control (Fig. 3). These decreases were nPKC dependent as they were inhibited with the pan-PKC inhibitor Gö6983 but not with the cPKC inhibitor Gö6976. PKC inhibitors alone had no effect on cell cycle activity of CF when compared with DMSO. The partial PKC agonist HMI-1b11 had no effect on BrdU-positive cells but induced a 15\% (95\% CI 0-30) decrease in Ki67positive cells.

The Effect of PKC Agonists and Inhibitors on Gene Expression in Cardiac Fibroblasts. To study the effects of $\mathrm{PKC}$ activation on the expression of genes related to cardiac fibrosis, we analyzed mRNA levels with qPCR after treating CFs with the PKC agonists and/or inhibitors for 48 hours. Both PKC agonists decreased the expression of several genes that encode structural proteins of cardiac extracellular matrix (Fig. 4). PMA decreased the expression of type I and III 


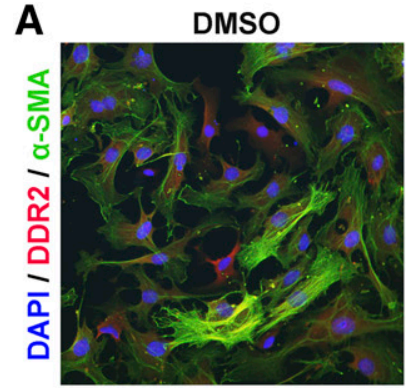

PMA + Gö6976
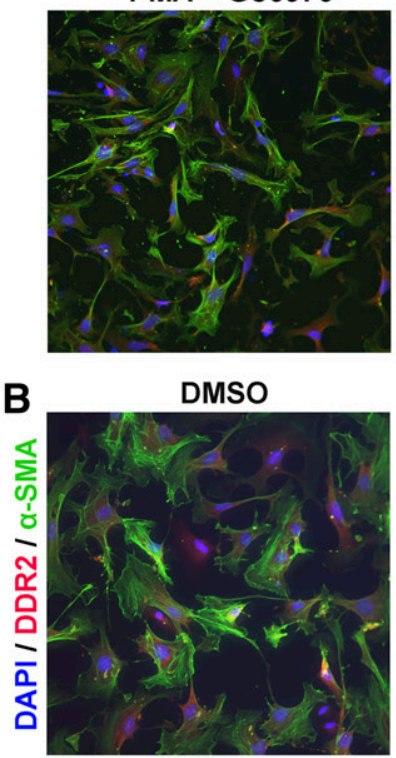

HMI-1b11 + Gö6976

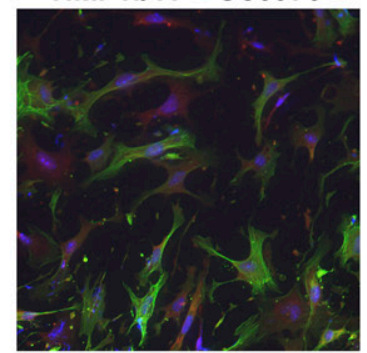

C

C

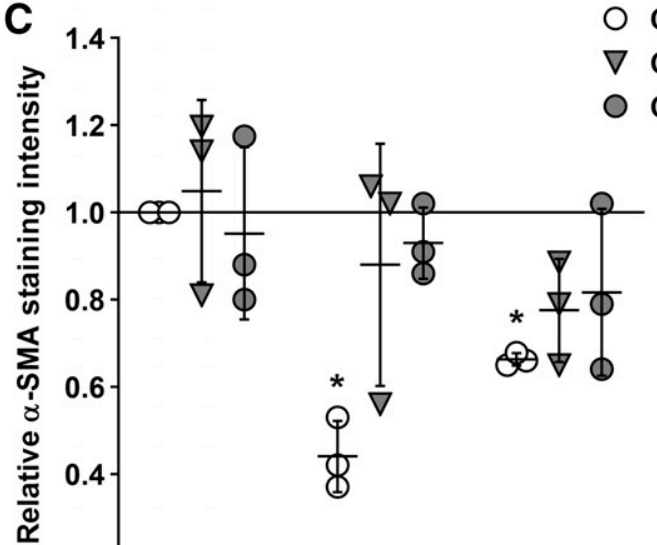

0.2 DMSO PMA HMI-1b11

Fig. 2. The effect of PKC agonists and inhibitors on $\alpha$-SMA expression in primary cardiac fibroblasts isolated from adult mice. The cells were exposed to PKC agonists (10 nM PMA or $10 \mu \mathrm{M}$ HMI-1b11) with or without PKC inhibitors (1 $\mu \mathrm{M}$ Gö6976, $1 \mu \mathrm{M}$ Gö6983) 24 hours after plating for 48 hours. At 72 hours after plating, the cells were fixed and collagen-encoding genes Col1a1 (47\%; 95\% CI 34-60; $P=$ 0.003; Fig. 4A) and Col3a1 (64\%; 95\% CI 59-69; $P<0.001$; Fig. 4C) and tended to decrease Col1a2 (26\%; 95\% CI 15-37; Fig. 4B) as well as glycoprotein fibronectin-encoding Fn1 gene (30\%; 95\% CI 17-43; Fig. 4D). Compound HMI-1b11 decreased the expression of Col3a1 (53\%; 95\% CI 43-63; $P=0.007$; Fig. 4C) and slightly $F n 1$ (22\%; 95\% CI 15-29; Fig. 4D) compared with DMSO-control. All of these decreases were nPKC dependent as they were inhibited or attenuated with the pan-PKC inhibitor Gö6983 but not with the cPKC inhibitor Gö6976. In fact, coexposure to Gö6976 tended to further decrease the mRNA levels of these structural protein-encoding genes, in particular with the weaker PKC activator HMI-1b11.

The expression of Postn gene that encodes for the matricellular protein periostin decreased after a 48-hour exposure to PKC agonists (Fig. 4E): 60\% in PMA-treated cells (95\% CI $39-81 ; P=0.005)$ and $48 \%$ in HMI-1b11-treated cells $(95 \% \mathrm{CI}$ 28-68; $P=0.022$ ). The effect was inhibited with both inhibitors, suggesting it was cPKC dependent. At the same time, the mRNA level of Acta2 that encodes contractile protein $\alpha$-SMA was not affected by exposure to PMA but was $36 \%$ lower (95\% CI 34-38; $P=0.004)$ in HMI-1b11-treated cells when compared with control (Fig. 4F). The cPKC inhibitor Gö6976 increased the transcription of Acta2 with or without coexposure to PKC agonists, whereas the pan-PKC inhibitor Gö6983 had no effect on Acta2 expression. Expression of TGF $\beta 1$-encoding gene Tgfb 1 was upregulated by HMI$1 \mathrm{~b} 11$ (54\%; 95\% CI 34-74; $P=0.019$ ), whereas coexposure to the inhibitors, especially Gö6983, attenuated the effect (Fig. 4G). Gö6976 alone increased the expression of Tcf21 (transcription factor 21 encoding) gene $(P=0.011$; Fig. $4 \mathrm{H})$ compared with DMSO. Similarly, coexposure to PMA and Gö6983 increased Tcf21 mRNA levels when compared with DMSO $(P=0.023)$. Gö6976, with or without coexposure to the PKC agonists, tended to slightly increase the expression of Myh10 (myosin heavy chain 10 encoding gene) as well (Fig. 4I).

Moreover, PKC agonists and inhibitors had distinct effects on the expression of $M m p 2$ (Fig. 4J) and Mmp9 (Fig. 4K) that encode matrix metalloproteinases. PMA or HMI-1b11 alone had no effect on the expression of $\mathrm{Mmp2}$, whereas coexposure to the cPKC inhibitor Gö6976 increased the expression when compared with DMSO-control: PMA + Gö6976, 52\% (95\% CI $2-102 ; P=0.037)$, and HMI-1b11 + Gö6976, 80\% (95\% CI $27-133 ; P=0.014)$. On the other hand, the expression of $M m p 9$ increased 2.6-fold (95\% CI 1.6-3.7; $P=0.035$ ) compared with control after a 48-hour exposure to PMA. In HMI-1b11-treated cells the increase was more modest (1.3-fold; 95\% CI 0.7-1.8). In both cases the effect was attenuated with coexposure to Gö6976 and Gö6983, suggesting it was cPKC dependent.

\section{Discussion}

Although numerous studies have been published regarding the role of $\mathrm{PKC}$ in heart failure, the results are conflicting and

stained. (A and B) Representative images of $\alpha$-SMA staining. Original magnification, $20 \times$. (C) Quantified intensity of $\alpha$-SMA staining. Results are displayed as scatter plots showing data values from independent experiments $(n=3)$, with means indicated by a line and error bars representing S.D. The data are normalized to DMSO-control. $* \mathrm{P}^{<} 0.05$ vs. DMSO-control (randomized block ANOVA followed by Dunnett's post hoc test) 

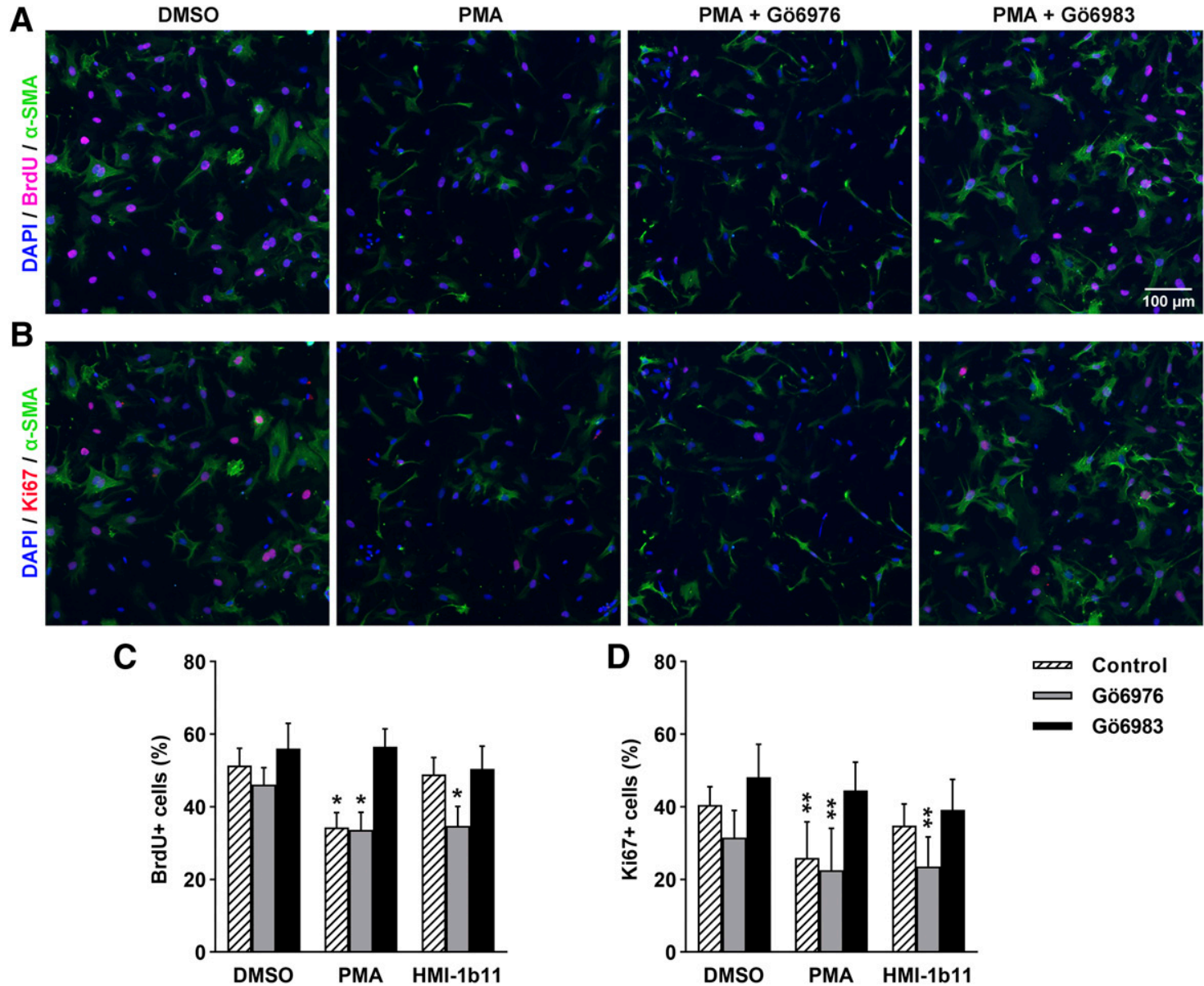

Fig. 3 The effect of PKC agonists and inhibitors on cell cycle activity of primary cardiac fibroblasts isolated from adult mice. The cells were exposed to PKC agonists (10 nM PMA or $10 \mu$ M HMI-1b11) with or without PKC inhibitors (1 $\mu$ M Gö6976, $1 \mu$ M Gö6983) 24 hours after plating for 48 hours. At 72 hours after plating, the cells were fixed and stained. Representative images of BrdU (A) and Ki67 (B) staining. Original magnification, 10×. Quantifications for the proportion of BrdU-positive cells (C) and Ki67-positive cells (D). Results are expressed as means + S.D. $(n=3)$. ${ }^{*} \mathrm{P}<0.05$ vs. DMSOcontrol (randomized block ANOVA followed by Dunnett's post hoc test); **P< 0.01 vs. DMSO-control.

sometimes difficult to interpret. Moreover, the roles of individual PKC isoforms in CF proliferation and transdifferentiation, two central processes in the development of fibrosis, and the potential of targeting PKC with pharmacological compounds to inhibit pathologic fibrosis have not been fully elucidated. Therefore, in this study our aim was to characterize CF proliferation, phenotype, and gene expression in response to selected proprietary and commercially available PKC agonists and inhibitors.

Overall, previous reports suggest that PKC isoforms play a role in cardiac fibrosis and remodeling. Their partially overlapping and redundant roles as well as compensatory changes in the expression of other PKC isoforms in knockdown models, however, complicate the interpretation of the results and may explain the sometimes conflicting outcomes (Klein et al., 2005; Gallegos and Newton, 2008; Song et al., 2015). Furthermore, the effect of PKC activation or inhibition is often cell type and stimulus dependent. In addition, the contextdependent regulation of PKC activity is not thoroughly understood. Using pharmacological tools for modulating PKC is not straightforward either as even compounds that were originally reported to be isoform selective have proven to exert cellular actions also via other PKC isoforms and kinases
(Steinberg and Sussman, 2005; Wu-Zhang and Newton, 2013). Additionally, not much is known about the role of PKC specifically in CFs. Most reports concerning the effects of $\mathrm{PKC}$ in cardiac fibrosis are from in vivo studies, which makes it difficult to decipher whether the effects on fibroblasts are direct or indirect. Better understanding of the role of PKC in $\mathrm{CF}$ activation would help the identification of the PKC isoforms that could serve as therapeutic targets for the treatment of adverse myocardial remodeling.

All PKC agonists and modulators used in this study proved to be relatively nontoxic to mouse CFs. Only compounds HMI$1 \mathrm{~b} 11$ and Gö6976 with the highest concentrations tested (30 $\mu \mathrm{M}$ and $10 \mu \mathrm{M}$, respectively) showed substantial toxicity. Based on the HCA, PMA-induced activation of nPKCs decreased CF proliferation. Parallel decrease in the viability of PMA-treated cells, as measured by the MTT assay, may also be explained with decreased cell division and thus lower cell density compared with control. Based on current knowledge, the activation and proliferation of resident fibroblasts represent the most important source of myofibroblasts in the fibrotic heart (Tallquist and Molkentin, 2017). Thus, inhibiting both CF transdifferentiation and proliferation might have potential as a therapeutic strategy for pathologic fibrosis. In 

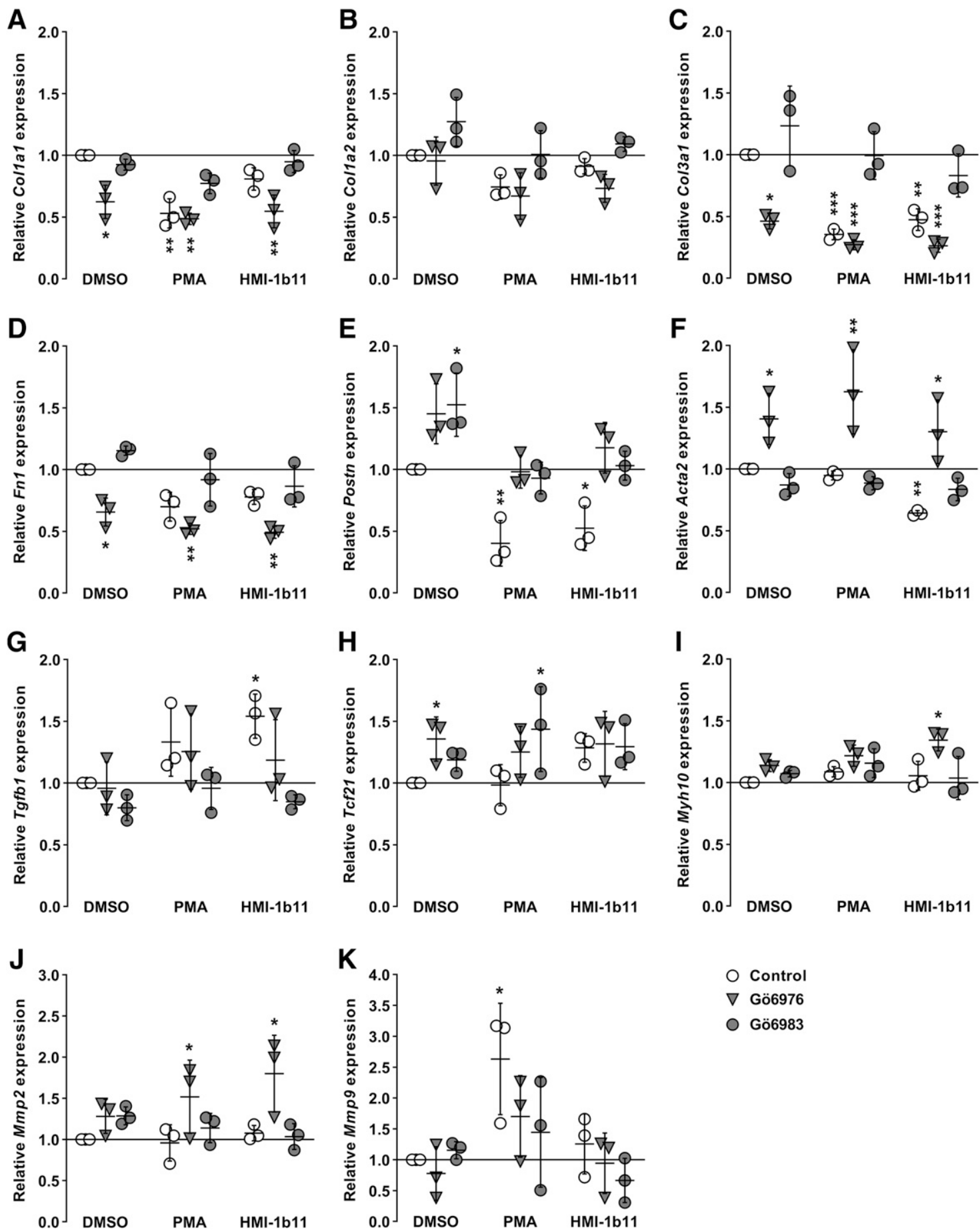

Fig. 4. The effect of $\mathrm{PKC}$ agonists and inhibitors on gene expression in primary cardiac fibroblasts isolated from adult mice. The cells were exposed to PKC agonists (10 nM PMA or $10 \mu$ M HMI-1b11) with or without PKC inhibitors (1 $\mu$ M Gö6976, $1 \mu$ M Gö6983) 24 hours after plating for 48 hours. At 72 hours after plating, mRNA was extracted and measured by qPCR. The levels of transcripts were adjusted to the average of two housekeeping genes (18S and Actb) from the same samples. (A) Col1a1. (B) Col1a2. (C) Col3a1. (D) Fn1. (E) Postn. (F) Acta2. (G) Tgfb1. (H) Tcf21. (I) Myh10. (J) Mmp2. (K) Mmp9. Results are displayed as scatter plots showing data values from independent experiments $(n=3)$, with means indicated by a line and error bars representing S.D. The data are normalized to DMSO-control. * $\mathrm{P}<0.05$ vs. DMSO-control (randomized block ANOVA followed by Dunnett's post hoc test); ** $\mathrm{P}<0.01$ vs. DMSO-control; *** $\mathrm{P}<0.001$ vs. DMSO-control.

our study, both PKC agonists decreased $\alpha$-SMA expression, a hallmark of CF transdifferentiation, although PMA was more effective compared with partial agonist HMI-1b11. In addition to $\alpha$-SMA, periostin has been described as an underlying marker of cardiac myofibroblasts (Kanisicak et al., 2016). In our study, the changes observed in the expression of
Postn in response to $\mathrm{PKC}$ activators and inhibitors were comparable to the changes noted in $\alpha$-SMA protein levels. Taken together, our results suggest that $\mathrm{cPKCs}$ are responsible for the PKC activator-induced inhibition of CF transdifferentiation. Moreover, the expression of collagen-encoding genes showed comparable nPKC-dependent regulation in 
response to $\mathrm{PKC}$ agonists and inhibitors as cell proliferation, indicating that PKC agonists may attenuate the production of new matrix proteins.

Interestingly, the changes seen in Acta 2 mRNA levels were not parallel to those in $\alpha$-SMA protein levels. This poor correlation between gene and protein expression could be due to timing: both analyses were done after 48-hour compound exposures ( 72 hours after cell isolation). Additionally, it is possible that $\mathrm{PKC}$ activation does not actually regulate $\alpha$-SMA expression on mRNA level but on later stages of the protein synthesis or degradation processes. Another interesting finding was the Gö6976-induced increase in Acta2 mRNA levels, with or without coexposure to PKC agonists. Considering Gö6976 has been shown to be a highly promiscuous inhibitor of other kinases besides classic PKC isoenzymes (Davies et al., 2000; Anastassiadis et al., 2011), it can be speculated that this effect on Acta2 expression is likely PKC independent.

Although several different markers used in the present study were regulated by PKC agonists and inhibitors, not all genes generally associated with fibrosis were affected, or the effect was ambiguous. This in part demonstrates the complex nature of fibrosis and the numerous factors that take part in regulating fibrotic responses. Eventually, what takes place on tissue level depends not only on the sum of all different factors but also on cooperation between different cell types. This can, for example, explain the unexpected increase in $T g f b 1$ expression in CFs in response to PKC agonists. Although TGF $\beta$ induces myofibroblast transdifferentiation and enhances collagen production (Petrov et al., 2002), it is produced by several cell types in vivo and has multiple functions and roles in cardiac tissue during injury and remodeling (Dobaczewski et al., 2011).

Based on our previous RNA sequencing data (Talman et al., 2018), the main cPKCs and nPKCs expressed in adult mouse heart are $\alpha, \delta, \varepsilon$, and $\eta$, which coincides with the analysis from Schreiber et al. (2001). Our present results indicate that the main cPKC isoform in mouse $\mathrm{CFs}$ is $\mathrm{PKC} \alpha$, moreover suggesting that $\mathrm{PKC} \alpha$ regulates myofibroblast transdifferentiation. This is in line with the study by Gao et al. (2003), which showed that inhibition of PKC with calphostin $\mathrm{C}$ or deletion of $\operatorname{PKC} \alpha$ with antisense $\mathrm{PKC} \alpha$ oligodeoxynucleotides inhibited TGF $\beta$-induced $\alpha$-SMA expression in rat aortic adventitial fibroblasts. Furthermore, we show that the main nPKCs expressed in the mouse heart are also expressed in CFs, thus suggesting that proliferation and collagen production in $\mathrm{CFs}$ are regulated via $\mathrm{PKC} \delta, \mathrm{PKC} \varepsilon$, and/or $\mathrm{PKC} \eta$. On the other hand, long-term PKC activation by PMA causes downregulation of PKC protein levels through proteasomedependent and -independent degradation (Young et al., 1987). Interestingly, 48-hour exposures to PMA (at $10 \mathrm{nM}$ ) or HMI-1b11 (at $10 \mu \mathrm{M}$ ) tended to downregulate $\mathrm{PKC} \delta$, but not other isoenzymes. This minor downregulation was comparable to that reported in SH-SY5Y neuroblastoma cells after a 24-hour exposure to $10 \mu \mathrm{M}$ HMI-1b11, but not as noticeable as in SH-SY5Y cells or cardiomyocytes treated with 100 nM PMA (Johnson et al., 1995; Sarajärvi et al., 2018). This together with our data demonstrating nPKCmediated ERK1/2 activation in response to PMA or HMI$1 \mathrm{~b} 11$ further support the conclusion that the observed effects are due to PKC activation and not inhibition by downregulation.
It is noteworthy that the cells used were isolated from healthy adult female mice. PKC isoform expressions and thereby PKC-mediated signaling may change in diseased state, likely resulting in changes in the effects of PKCtargeted compounds. Furthermore, it is possible that the age and the sex of the animals used could explain some of the discrepancies of the present results with previous studies. However, as most of the previous work has been conducted in vivo and using rats, we consider that the drastic difference of in vivo and in vitro conditions as well as the species differences are more plausible causes for the discrepancies observed. Another limitation of the present study are the pharmacological tools targeting multiple PKC isoenzymes but also other kinases. However, parallel usage of Gö6976 and Gö6983 provides a valuable tool to analyze whether an effect is a result of $\mathrm{nPKC}$ activity or cPKC activity or is $\mathrm{PKC}$ independent. Furthermore, using the inhibitors in combination with C1 domain-targeting PKC activators, which only bind to two other serine-threonine kinases, protein kinase $\mathrm{D}$ and dystrophy kinase-related Cdc42 binding kinase (ColónGonzález and Kazanietz, 2006; Talman et al., 2014a), further strengthens the conclusion of PKC-mediated effects. Isoenzyme-specific silencing could be used to investigate the role of individual PKC isoforms in CFs. Redundant roles of closely related PKC isoforms and compensatory expression changes in other isoforms may, however, limit the conclusions from such experiments. Furthermore, PKC also has noncatalytic functions (Ling et al., 2007; Cameron et al., 2008; Zeidman et al., 1999), mainly via protein-protein interactions, and thus genetic silencing and pharmacological tools targeting certain PKC isoforms may not always produce similar functional outcomes.

In conclusion, by characterizing mouse CFs in response to several different PKC agonists and inhibitors, we revealed that PKC agonists (1) inhibit CF transdifferentiation into myofibroblasts, (2) decrease CF proliferation, and (3) decrease expression of collagen-encoding genes in CFs. Moreover, we discovered that $\mathrm{CF}$ transdifferentiation is regulated via cPKCs, whereas CF proliferation and collagen gene expression are regulated via $n$ PKCs. Overall, our results suggest that activation of PKC in CFs may be a promising strategy to inhibit pathologic cardiac remodeling. As downregulation of $\mathrm{PKC}$ in response to irreversible PKC activation by ultrapotent PKC agonists such as PMA is considered to cause tumor promotion previously attributed to PKC activation (Antal et al., 2015; Newton and Brognard, 2017), weaker or partial agonists that do not downregulate PKC completely, such as the isophthalate HMI-1b11, represent promising leads for PKC-targeted antifibrotic therapies. Further studies in multicellular environment and pathophysiological context are, however, required to establish proof of concept.

\section{Acknowledgments}

We thank Dr. Sini Kinnunen and Timo Myöhänen for sharing their expertise in the research methods, Dr. Harri Jäälinoja for providing support for the phenotypic analysis, and Annika Korvenpää for her technical assistance. Jari Yli-Kauhaluoma and Riccardo Provenzani (University of Helsinki) are kindly acknowledged for providing the compound HMI-1b11. The Light Microscopy Unit (Institute of Biotechnology and Helsinki Institute of Life Science, University of Helsinki) is acknowledged for providing instrumentation for the phenotypic analysis. The Biomedicum Imaging Unit (Helsinki Institute 
of Life Science, University of Helsinki) is acknowledged for providing instrumentation for the HCA.

\section{Authorship Contributions}

Participated in research design: Karhu, Ruskoaho, Talman. Conducted experiments: Karhu.

Performed data analysis: Karhu, Talman.

Contributed to the writing of the manuscript: Karhu, Ruskoaho, Talman.

\section{References}

Anastassiadis T, Deacon SW, Devarajan K, Ma H, and Peterson JR (2011) Comprehensive assay of kinase catalytic activity reveals features of kinase inhibitor selectivity. Nat Biotechnol 29:1039-1045.

Antal CE, Hudson AM, Kang E, Zanca C, Wirth C, Stephenson NL, Trotter EW, Gallegos LL, Miller CJ, Furnari FB, et al. (2015) Cancer-associated protein kinase C mutations reveal kinase's role as tumor suppressor. Cell 160:489-502.

Boije af Gennäs G, Talman V, Yli-Kauhaluoma J, Tuominen RK, and Ekokoski E (2011) Current status and future prospects of $\mathrm{C} 1$ domain ligands as drug candidates. Curr Top Med Chem 11:1370-1392.

Boije af Gennäs G, Talman V, Aitio O, Ekokoski E, Finel M, Tuominen RK, and YliKauhaluoma J (2009) Design, synthesis, and biological activity of isophthalic acid derivatives targeted to the C1 domain of protein kinase C. J Med Chem 52: 3969-3981.

Bowling N, Walsh RA, Song G, Estridge T, Sandusky GE, Fouts RL, Mintze K, Pickard T, Roden R, Bristow MR, et al. (1999) Increased protein kinase C activity and expression of $\mathrm{Ca} 2+-$ sensitive isoforms in the failing human heart. Circulation 99:384-391.

Boyle AJ, Kelly DJ, Zhang Y, Cox AJ, Gow RM, Way K, Itescu S, Krum H, and Gilbert $\mathrm{RE}$ (2005) Inhibition of protein kinase $\mathrm{C}$ reduces left ventricular fibrosis and dysfunction following myocardial infarction. J Mol Cell Cardiol 39:213-221.

Braun MU and Mochly-Rosen D (2003) Opposing effects of $\delta$ - and $\zeta$-protein kinase C isozymes on cardiac fibroblast proliferation: use of isozyme-selective inhibitors. J Mol Cell Cardiol 35:895-903.

Cameron AJ, Procyk KJ, Leitges M, and Parker PJ (2008) PKC alpha protein but not kinase activity is critical for glioma cell proliferation and survival. Int $J$ Cancer 123:769-779

Cohn JN, Ferrari R, and Sharpe N (2000) Cardiac remodeling--concepts and clinical implications: a consensus paper from an international forum on cardiac remodeling. Behalf of an International Forum on Cardiac Remodeling. J Am Coll Cardiol 35:569-582.

Colón-González F and Kazanietz MG (2006) C1 domains exposed: from diacylglycerol binding to protein-protein interactions. Biochim Biophys Acta 1761:827-837.

Connelly KA, Kelly DJ, Zhang Y, Prior DL, Advani A, Cox AJ, Thai K, Krum H, and Gilbert RE (2009) Inhibition of protein kinase C- $\beta$ by ruboxistaurin preserves cardiac function and reduces extracellular matrix production in diabetic cardiomyopathy. Circ Heart Fail 2:129-137.

Davies SP, Reddy H, Caivano M, and Cohen P (2000) Specificity and mechanism of action of some commonly used protein kinase inhibitors. Biochem $J$ 351:95-105.

Dobaczewski M, Chen W, and Frangogiannis NG (2011) Transforming growth factor (TGF)- $\beta$ signaling in cardiac remodeling. $J$ Mol Cell Cardiol 51:600-606.

Ferreira JC, Koyanagi T, Palaniyandi SS, Fajardo G, Churchill EN, Budas G, Disatnik MH, Bernstein D, Brum PC, and Mochly-Rosen D (2011) Pharmacological inhibition of $\beta$ IIPKC is cardioprotective in late-stage hypertrophy. $J$ Mol Cell Cardiol 51:980-987.

Gallegos LL and Newton AC (2008) Spatiotemporal dynamics of lipid signaling: protein kinase $\mathrm{C}$ as a paradigm. IUBMB Life 60:782-789.

Gao PJ, Li Y, Sun AJ, Liu JJ, Ji KD, Zhang YZ, Sun WL, Marche P, and Zhu DL (2003) Differentiation of vascular myofibroblasts induced by transforming growth factor- $\beta 1$ requires the involvement of protein kinase Calpha. J Mol Cell Cardiol 35:1105-1112.

Goldsmith EC, Hoffman A, Morales MO, Potts JD, Price RL, McFadden A, Rice M, and Borg TK (2004) Organization of fibroblasts in the heart. Dev Dyn 230:787-794.

Gulati A, Jabbour A, Ismail TF, Guha K, Khwaja J, Raza S, Morarji K, Brown TD, Ismail NA, Dweck MR, et al. (2013) Association of fibrosis with mortality and sudden cardiac death in patients with nonischemic dilated cardiomyopathy. JAMA 309:896-908

Inagaki K, Koyanagi T, Berry NC, Sun L, and Mochly-Rosen D (2008) Pharmacological inhibition of $\varepsilon$-protein kinase $\mathrm{C}$ attenuates cardiac fibrosis and dysfunction in hypertension-induced heart failure. Hypertension 51:1565-1569.

Johnson JA, Adak S, and Mochly-Rosen D (1995) Prolonged phorbol ester treatment down-regulates protein kinase $\mathrm{C}$ isozymes and increases contraction rate in neonatal cardiac myocytes. Life Sci 57:1027-1038.

Kanisicak O, Khalil H, Ivey MJ, Karch J, Maliken BD, Correll RN, Brody MJJ, J Lin SC, Aronow BJ, Tallquist MD, et al. (2016) Genetic lineage tracing defines myofibroblast origin and function in the injured heart. Nat Commun 7:12260.

Karhu ST, Välimäki MJ, Jumppanen M, Kinnunen SM, Pohjolainen L, Leigh RS, Auno S, Földes G, Boije Af Gennäs G, Yli-Kauhaluoma J, et al. (2018) Stem cells are the most sensitive screening tool to identify toxicity of GATA4-targeted novel small-molecule compounds. Arch Toxicol 92:2897-2911.

Klein G, Schaefer A, Hilfiker-Kleiner D, Oppermann D, Shukla P, Quint A, Podewski E, Hilfiker A, Schröder F, Leitges M, et al. (2005) Increased collagen deposition and diastolic dysfunction but preserved myocardial hypertrophy after pressure overload in mice lacking PKCepsilon. Circ Res 96:748-755.

Kong P, Christia P, and Frangogiannis NG (2014) The pathogenesis of cardiac fibrosis. Cell Mol Life Sci 71:549-574.
Ling M, Sunesson L, and Larsson C (2007) Comparison of the PKCalpha and the PKCepsilon C1b domains: identification of residues critical for PKCepsilonmediated neurite induction. J Mol Biol 368:951-965.

Liu Q, Chen X, Macdonnell SM, Kranias EG, Lorenz JN, Leitges M, Houser SR, and Molkentin JD (2009) Protein kinase C $\alpha$, but not PKC $\beta$ or PKC $\gamma$, regulates contractility and heart failure susceptibility: implications for ruboxistaurin as a novel therapeutic approach. Circ Res 105:194-200.

Mackay HJ and Twelves CJ (2007) Targeting the protein kinase C family: are we there yet? Nat Rev Cancer 7:554-562.

Mochly-Rosen D, Das K, and Grimes KV (2012) Protein kinase C, an elusive therapeutic target? Nat Rev Drug Discov 11:937-957.

Newton AC and Brognard J (2017) Reversing the paradigm: protein kinase C as a tumor suppressor. Trends Pharmacol Sci 38:438-447.

Palaniyandi SS, Sun L, Ferreira JC, and Mochly-Rosen D (2009) Protein kinase C in heart failure: a therapeutic target? Cardiovasc Res 82:229-239.

Petrov VV, Fagard RH, and Lijnen PJ (2002) Stimulation of collagen production by transforming growth factor- $\beta 1$ during differentiation of cardiac fibroblasts to myofibroblasts. Hypertension 39:258-263.

Sarajärvi T, Jäntti M, Paldanius KMA, Natunen T, Wu JC, Mäkinen P, Tarvainen I, Tuominen RK, Talman V, and Hiltunen M (2018) Protein kinase C -activating isophthalate derivatives mitigate Alzheimer's disease-related cellular alterations. Neuropharmacology 141:76-88.

Schreiber KL, Paquet L, Allen BG, and Rindt H (2001) Protein kinase C isoform expression and activity in the mouse heart. Am J Physiol Heart Circ Physiol 281: H2062-H2071.

Schönwasser DC, Marais RM, Marshall CJ, and Parker PJ (1998) Activation of the mitogen-activated protein kinase/extracellular signal-regulated kinase pathway by conventional, novel, and atypical protein kinase C isotypes. Mol Cell Biol 18: $790-798$

Shin HG, Barnett JV, Chang P, Reddy S, Drinkwater DC, Pierson RN, Wiley RG, and Murray KT (2000) Molecular heterogeneity of protein kinase C expression in human ventricle. Cardiovasc Res 48:285-299.

Shinde AV and Frangogiannis NG (2014) Fibroblasts in myocardial infarction: a role in inflammation and repair. $J \mathrm{Mol}$ Cell Cardiol 70:74-82.

Simonis G, Briem SK, Schoen SP, Bock M, Marquetant R, and Strasser RH (2007) Protein kinase $\mathrm{C}$ in the human heart: differential regulation of the isoforms in aortic stenosis or dilated cardiomyopathy. Mol Cell Biochem 305:103-111.

Song M, Matkovich SJ, Zhang Y, Hammer DJ, and Dorn GW II (2015) Combined cardiomyocyte $\mathrm{PKC} \delta$ and $\mathrm{PKC} \varepsilon$ gene deletion uncovers their central role in restraining developmental and reactive heart growth. Sci Signal 8:ra39.

Steinberg SF (2008) Structural basis of protein kinase C isoform function. Physiol Rev 88:1341-1378.

Steinberg SF and Sussman MA (2005) Cardiac hypertrophy served with protein kinase Cepsilon: $\delta$ isoform substitution available at additional cost. Circ Res 96: $711-713$.

Tallquist MD and Molkentin JD (2017) Redefining the identity of cardiac fibroblasts. Nat Rev Cardiol 14:484-491.

Talman V, Amadio M, Osera C, Sorvari S, Boije Af Gennäs G, Yli-Kauhaluoma J, Rossi D, Govoni S, Collina S, Ekokoski E, et al. (2013) The C1 domain-targeted isophthalate derivative HMI-1b11 promotes neurite outgrowth and GAP-43 expression through PKC $\alpha$ activation in SH-SY5Y cells. Pharmacol Res 73: $44-54$

Talman V, Gateva G, Ahti M, Ekokoski E, Lappalainen P, and Tuominen RK (2014a) Evidence for a role of MRCK in mediating HeLa cell elongation induced by the C1 domain ligand HMI-1a3. Eur J Pharm Sci 55:46-57.

Talman V, Provenzani R, Boije af Gennäs G, Tuominen RK, and Yli-Kauhaluoma J (2014b) C1 domain-targeted isophthalates as protein kinase C modulators: structure-based design, structure-activity relationships and biological activities. Biochem Soc Trans 42:1543-1549.

Talman V and Ruskoaho H (2016) Cardiac fibrosis in myocardial infarction-from repair and remodeling to regeneration. Cell Tissue Res 365:563-581.

Talman V, Teppo J, Pöhö P, Movahedi P, Vaikkinen A, Karhu ST, Trošt K, Suvitaival T, Heikkonen J, Pahikkala T, et al. (2018) Molecular atlas of postnatal mouse heart development. J Am Heart Assoc 7:e010378.

Talman V, Tuominen RK, Boije af Gennäs G, Yli-Kauhaluoma J, and Ekokoski E (2011) C1 Domain-targeted isophthalate derivatives induce cell elongation and cell cycle arrest in HeLa cells. PLoS One 6:e20053.

van den Borne SW, Diez J, Blankesteijn WM, Verjans J, Hofstra L, and Narula J (2010) Myocardial remodeling after infarction: the role of myofibroblasts. Nat Rev Cardiol 7:30-37.

Wang J, Chen H, Seth A, and McCulloch CA (2003) Mechanical force regulation of myofibroblast differentiation in cardiac fibroblasts. Am J Physiol Heart Circ Physiol 285:H1871-H1881.

Webb BL, Hirst SJ, and Giembycz MA (2000) Protein kinase C isoenzymes: a review of their structure, regulation and role in regulating airways smooth muscle tone and mitogenesis. Br J Pharmacol 130:1433-1452.

Wu-Zhang AX and Newton AC (2013) Protein kinase C pharmacology: refining the toolbox. Biochem J 452:195-209.

Young S, Parker PJ, Ullrich A, and Stabel S (1987) Down-regulation of protein kinase $\mathrm{C}$ is due to an increased rate of degradation. Biochem $J$ 244:775-779.

Zeidman R, Löfgren B, Pâhlman S, and Larsson C (1999) PKCepsilon, via its regulatory domain and independently of its catalytic domain, induces neurite-like processes in neuroblastoma cells. J Cell Biol 145:713-726.

Address correspondence to: Virpi Talman, Division of Pharmacology and Pharmacotherapy, Faculty of Pharmacy, University of Helsinki, P.O. Box 56 (Viikinkaari 5E), FI-00014 Helsinki, Finland. E-mail: virpi.talman@helsinki.fi 